\title{
Optimal Mutant Model of Human S100A3 Protein Citrullinated at Arg51 by Peptidylarginine Deiminase type III and Its Solution Structural Properties.
}

Kenji Ite ${ }^{1,2}$, Kento Yonezawa ${ }^{3}$, Kenichi Kitanishi ${ }^{1,2, \dagger}$, Nobutaka Shimizu ${ }^{3}$ and Masaki Unno ${ }^{1,2}$.

${ }^{1}$ Graduate School of Science and Engineering, Ibaraki University, 4-12-1 Nakanarusawa,

Hitachi, Ibaraki 316-8511, Japan

${ }^{2}$ Frontier Research Center for Applied Atomic Sciences, Ibaraki University, 162-2 Shirakata,

Naka, Ibaraki 319-1106, Japan

${ }^{3}$ High Energy Accelerator Research Organization Institute of materials Structure Science, 1-1

Ohho, Tsukuba, Ibaraki 300-3256, Japan

${ }^{\dagger}$ Present address: Faculty of Science, Tokyo University of Science, 1-3 Kagurazaka, Shinjuku, Tokyo, 162-8601, Japan

* Corresponding Authors: Masaki Unno

E-mail address: masaki.unno.19@vc.ibaraki.ac.jp 
Table S1. The $[\theta]_{222}$ and $\alpha$-helix content of WT, R51Z and the mutated S100A3 for the metal-free forms.

\begin{tabular}{ccc}
\hline $\begin{array}{c}\text { Protein } \\
(\mathrm{S} 100 \mathrm{~A} 3)\end{array}$ & $\begin{array}{c}{[\theta]_{222}} \\
\left(\mathrm{deg} \mathrm{cm}^{2} \mathrm{dmol}^{-1}\right)\end{array}$ & $\begin{array}{c}\alpha \text {-helix content } \\
(\%)\end{array}$ \\
\hline WT & -18250 & 52.5 \\
R51A & -18771 & 54.2 \\
R51C & -17231 & 49.1 \\
R51E & -16935 & 48.2 \\
R51K & -11467 & 30.1 \\
R51Q & -19209 & 55.7 \\
R51Z & -17722 & 50.8 \\
\hline
\end{tabular}

Table S2. The effects for $\mathrm{Ca}^{2+}$ and $\mathrm{Zn}^{2+}$ on $\alpha$-helix content of WT, R51Z and R51Q.

\begin{tabular}{ccccc}
\hline$\left[\mathrm{Zn}^{2+}\right] /[\mathrm{S} 100 \mathrm{~A} 3]$ & \multicolumn{2}{c}{$\alpha$-helix contants (\%) } & \multicolumn{2}{c}{ Disruption rate (\%) } \\
\cline { 2 - 5 } at 1 $\mathrm{mM} \mathrm{Ca}^{2+}$ & $\mathrm{R} 51 \mathrm{Z}$ & $\mathrm{R} 51 \mathrm{Q}$ & $\mathrm{R} 51 \mathrm{Z}$ & $\mathrm{R} 51 \mathrm{Q}$ \\
\hline MetalFree & 51.8 & 56.6 & 0 & 0 \\
0 & 49.4 & 53.9 & 4.6 & 4.8 \\
1 & 42.2 & 45.7 & 18.5 & 19.3 \\
2 & 39.0 & 43.0 & 24.7 & 24.0 \\
4 & 36.2 & 39.5 & 30.1 & 30.2 \\
\hline
\end{tabular}



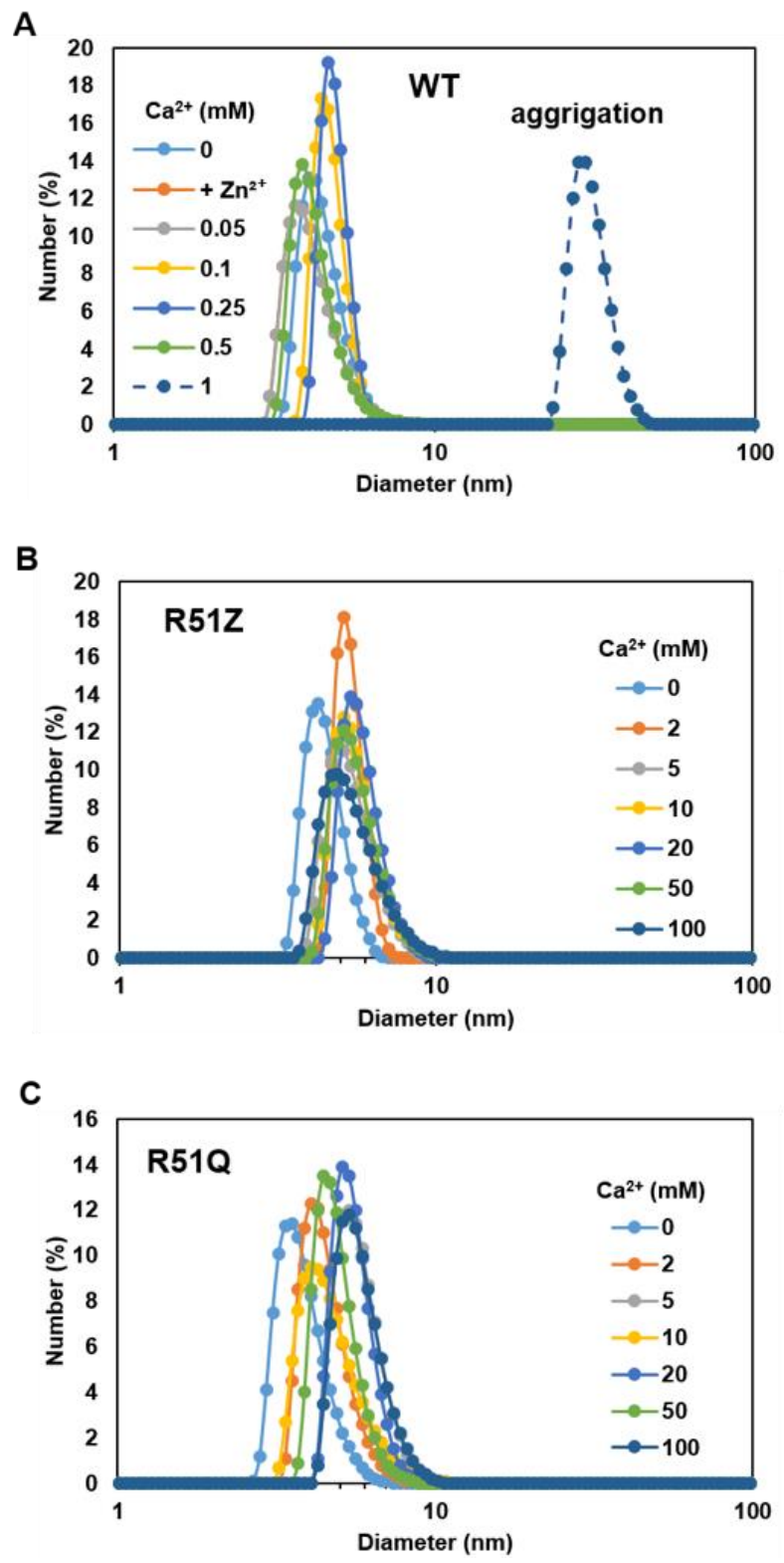

Figure S1. DLS analysis of changes in the molecular diameter of WT, R51Z and R51Q S100A3 (0.5 mM each) in the absence or presence of $\mathrm{Ca}^{2+} / \mathrm{Zn}^{2+}$. Each peak represents the mean value obtained from 10 independent experiments. A, The molecular diameter of WT increased significantly after the addition of $0.05,0.1,0.25,0.5$ and $1 \mathrm{mM} \mathrm{Ca}^{2+}$ at $0.5 \mathrm{mM} \mathrm{Zn}^{2+}$. In the presence of $1.0 \mathrm{mM} \mathrm{Ca}^{2+}$ and $0.5 \mathrm{mM} \mathrm{Zn}^{2+}$, WT was precipitate. B, C, The molecular diameter of R51Z (B) R51Q (C) at 0, 2, 5, 10, 20, 50 and $100 \mathrm{mM}$ $\mathrm{Ca}^{2+}$. 
A

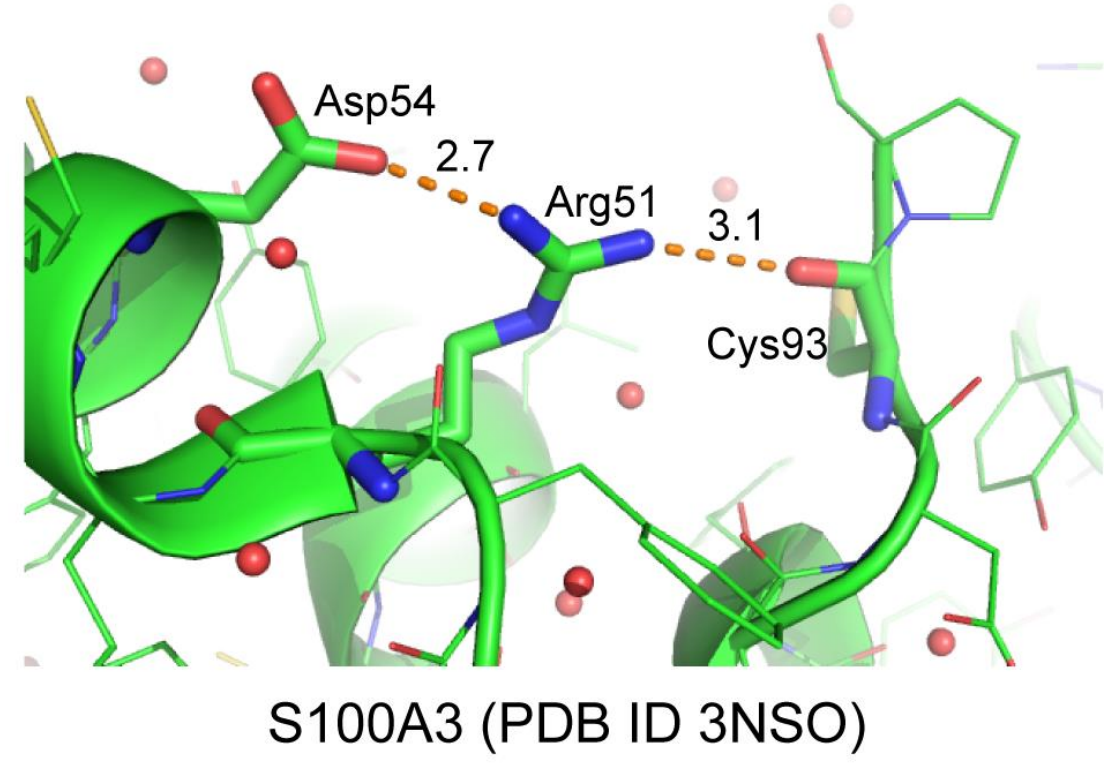

B

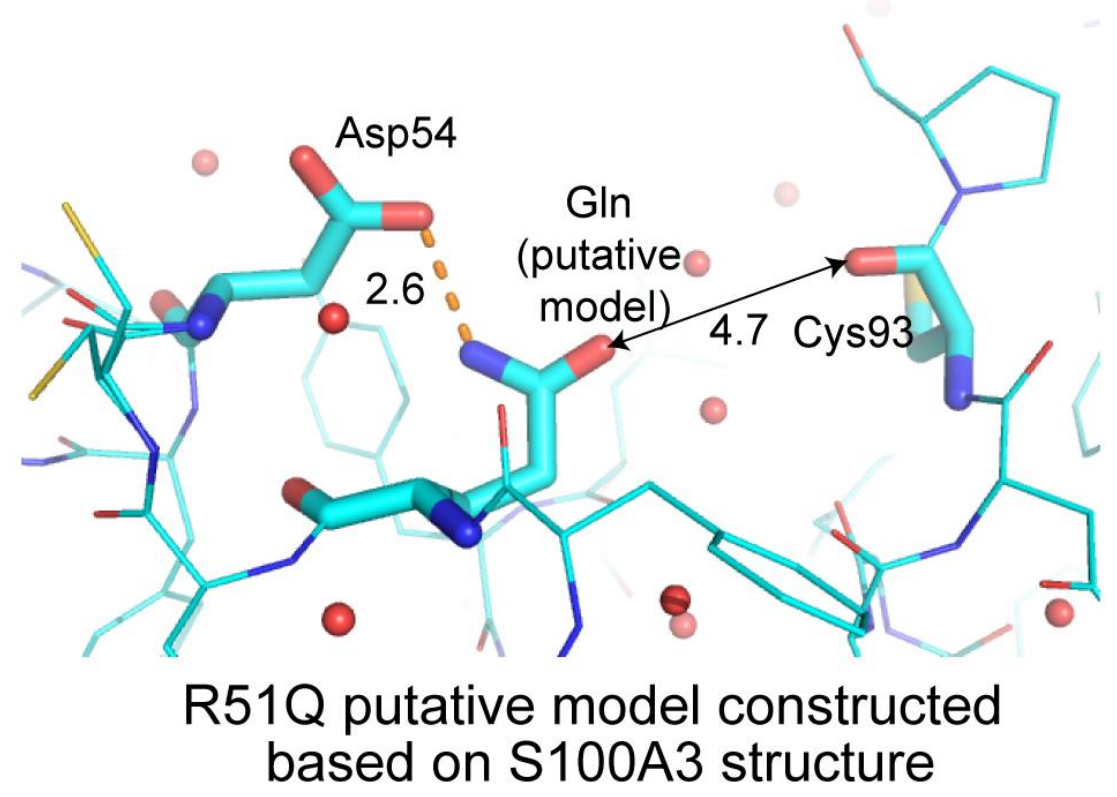

Figure S2. Putative role of Arg51. A Arg51 forms a salt bridge with Asp54 in helix III and also forms a hydrogen-bonding interaction with the main chain carbonyl O of Cys93 to stabilize structure of S100A3 (PDB ID, 3NSO). B One of the putative model of R51Q in which the hydrogen-bonding interaction between Gln51 and Cys93 main chain is lost. 


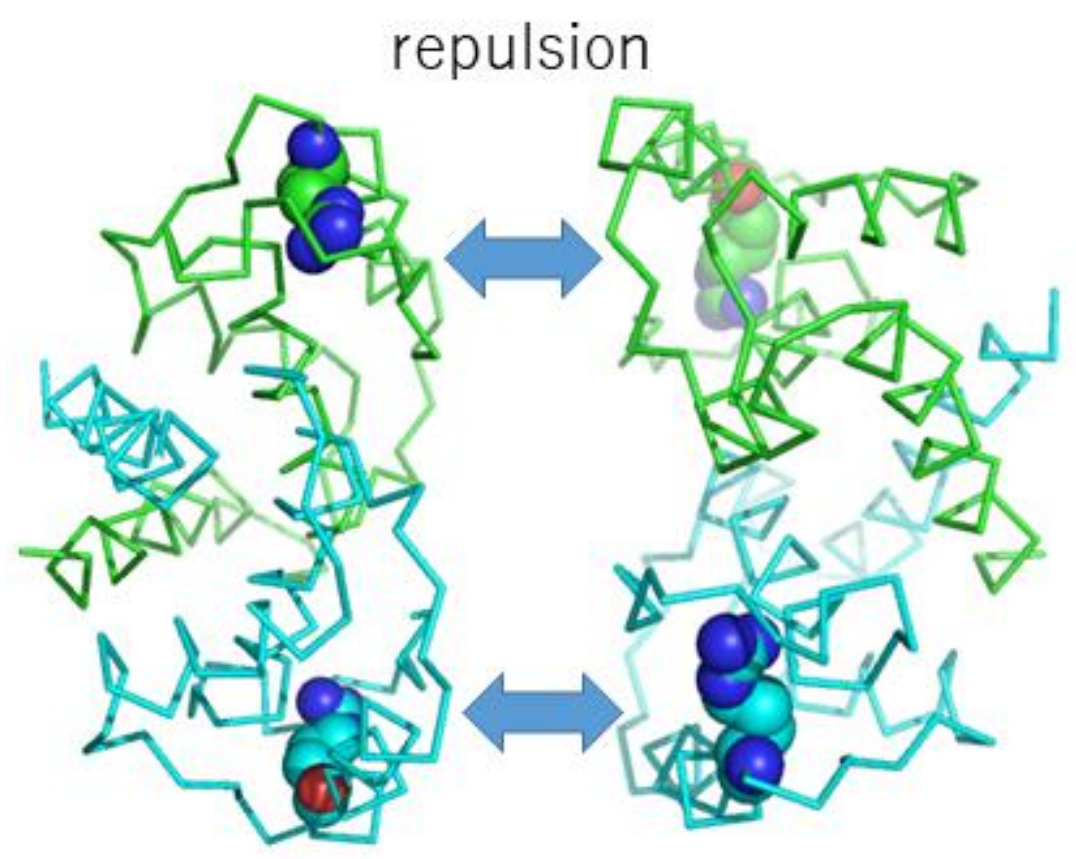

Figure S3. The dimers of WT S100A3 hardly change the structure, and the tetramer cannot be formed stably. Arg51s are located near the docking surface. CPK balls indicate atoms composing Arg51. 


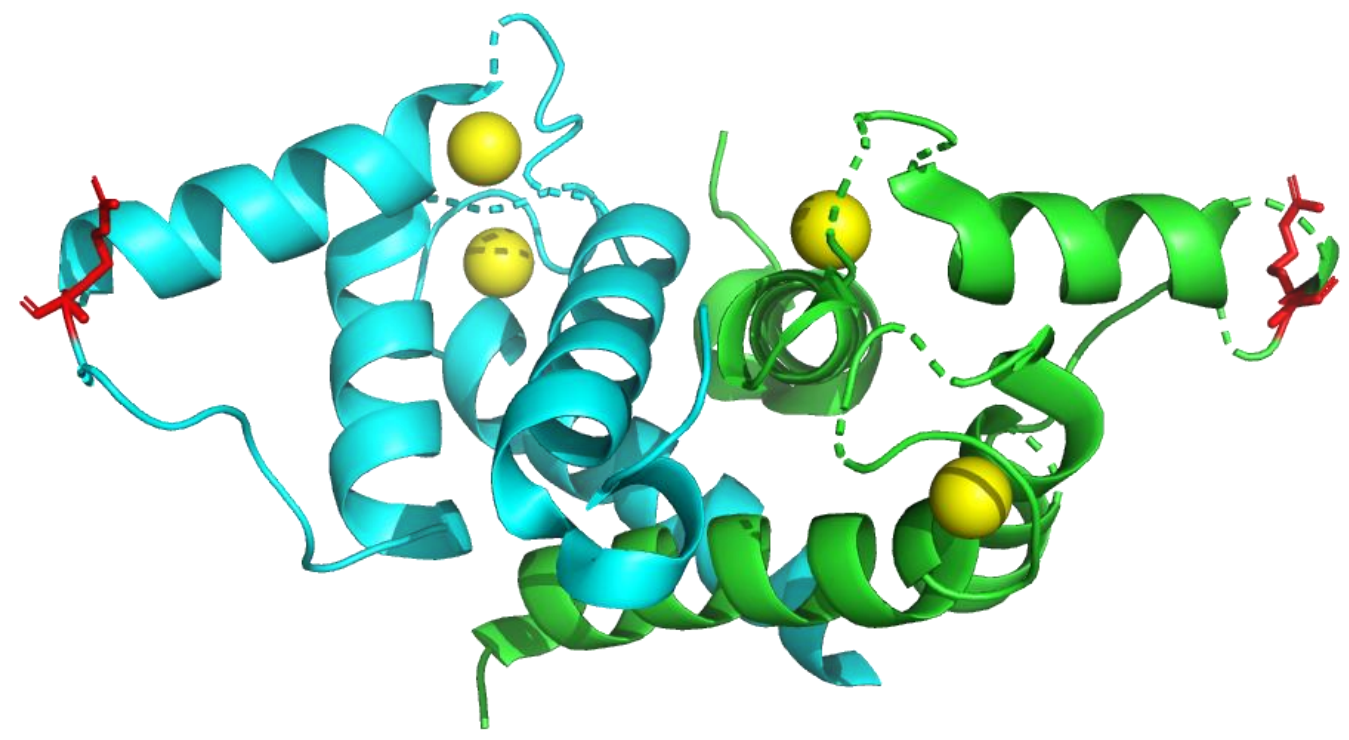

Figure S4. A putative $\mathrm{Ca}^{2+}$-bound model of $\mathrm{S} 100 \mathrm{~A} 3$ constructed based on the $\mathrm{Ca}^{2+}$-bound S100A4 (PDB codes, 3NSO and 3C1V). The yellow balls indicate $\mathrm{Ca}^{2+}$ ions. Arg51s were coloured in red. The regions that were not connected were drawn with dotted lines. Unless the secondary structures are destroyed, S100A3 will not have a completely connected correct structure. 


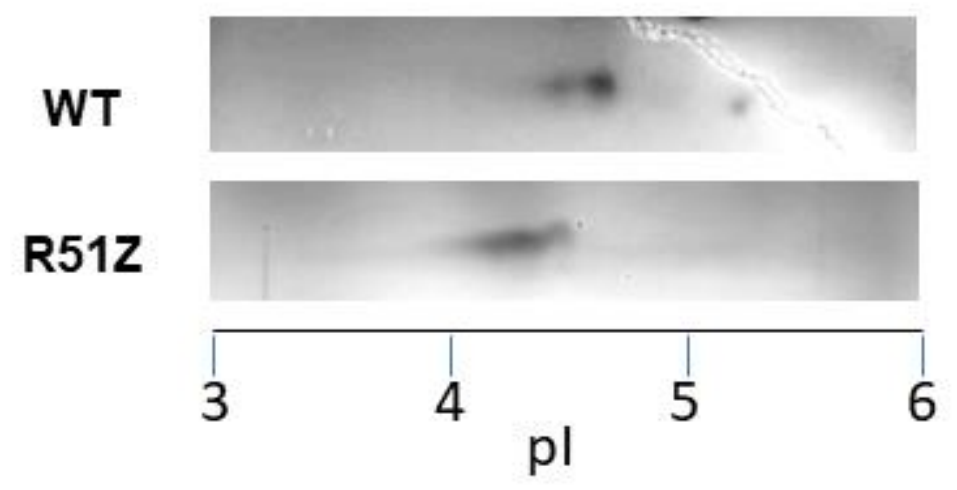

Figure S5. Citrullination of recombinant S100A3 was confirmed by 2-dimensional PAGE. WT and citrullinated form (R51Z) detected isoelectric pI 4.6 and 4.3, respectively. 
Table S3. SAS data acquisition, sample details, data analysis, and software used.

\begin{tabular}{|c|c|c|c|}
\hline A. Sample details & Metal-free WT & Metal-free R51Q & $\mathrm{R} 51 \mathrm{Q}\left(\mathrm{Ca}^{2+} / \mathrm{Zn}^{2+}\right)$ \\
\hline Organism & \multicolumn{3}{|c|}{ Homo sapiens (Human) } \\
\hline Source (Catalogue No. or reference) & \multicolumn{3}{|c|}{ E.coli expressed } \\
\hline Uniprot ID + (residues, tRNA) & \multicolumn{3}{|c|}{ P33764 } \\
\hline Extinction coefficient & \multicolumn{3}{|c|}{1.233} \\
\hline \multicolumn{4}{|l|}{$\left(\mathrm{A}_{280 \mathrm{~nm}}, \mathrm{Abs}_{0.1 \%}(\mathrm{w} / \mathrm{v})\right)$} \\
\hline Theoretical monomeric mass (Da) & \multicolumn{3}{|c|}{11713} \\
\hline Concentration range $\left(\mathrm{mg} \mathrm{ml}^{-1}\right)$ & \multirow[t]{2}{*}{$0.5-1.5$} & $0.45-1.25$ & \multirow[t]{2}{*}{$0.24-0.46$} \\
\hline $\begin{array}{l}\text { Concentration values measured and } \\
\text { method }\end{array}$ & & UV-Vis. spectrosco & \\
\hline Solvent composition & \multicolumn{2}{|c|}{$\begin{array}{c}50 \mathrm{mM} \text { TrisHCl, } 150 \mathrm{mM} \mathrm{NaCl}, 1 \mathrm{mM} \\
\text { DTT, pH } 7.6\end{array}$} & $\left(+2.5 \mathrm{mM} \mathrm{CaCl}_{2}\right)$ \\
\hline
\end{tabular}

\section{B. SAXS data collection}

Source, instrument

Wavelength $(\AA)$

Camera Length (mm)

Beam geometry $(\mu \mathrm{m})$

$q$-measurement range $\left(\AA^{-1}\right)$

Absolute scaling method

The normalization to constant counts

Method for monitoring radiation damage

Exposure time, number of exposures
Photon Factory BL-10C

1.5

1011.95

V350 $\times$ H550 Bent cylindrical mirror +2 slits +1 pinhole

0.0121-0.6088

Comparison with scattering from pure $\mathrm{H}_{2} \mathrm{O}$

Normalized to incident intensity by $\mu$ ion chamber

data frame-by-frame comparison

$20 \mathrm{sec}, 423$ images 
Sample configuration

Sample temperature (K) steel cell $(\mathrm{H} 1.5 \times \mathrm{W} 3.0 \times \mathrm{t} 1.0 \mathrm{~mm})$

293

\section{The software for SAXS data analysis}

\begin{tabular}{lccc}
\hline SAS data processing & \multicolumn{2}{c}{ SAngler $^{39}$, Serial Analyzer } \\
Calculation of $\varepsilon$ from sequence & ExPASy $^{37}$ & \\
\hline D. Structural parameters & Metal-free WT & Meta-free R51Q & R51Q $\left(\mathrm{Ca}^{2+} / \mathrm{Zn}^{2+}\right)$ \\
\hline$I(0)\left(\mathrm{cm}^{-1}\right)$ form Guinier & $0.026+/-0.0003$ & $0.027+/-0.0005$ & $0.071+/-0.005$ \\
& & & $30.3+/-1.4$ \\
$R_{\mathrm{g}}(\AA)$ form Guinier & $18.8+/-0.2$ & $19.0+/-0.4$ & $0.0135-0.0427$ \\
$Q$-range $(\AA-1)$ form Guinier & $0.0150-0.0691$ & $0.0142-0.0683$ & \\
\end{tabular}

